\title{
Development of the Composition and Modes of Spraying Antifriction Coating Reinforced with Quasicrystals for the Manufacture of Sliding Bearings
}

\author{
Silchenko Olga Borisovna*, Siluyanova Marina Vladimirovna \\ Department of Technology of Production and Operation of Aircraft Engines, Institute №12 MAI (National Research University), Moscow, \\ Russia \\ Email address: \\ silyaolya@yandex.ru (S. O. Borisovna),dc2mati@yandex.ru (S. M. Vladimirovna) \\ ${ }^{*}$ Corresponding author

\section{To cite this article:} \\ Silchenko Olga Borisovna, Siluyanova Marina Vladimirovna. Development of the Composition and Modes of Spraying Antifriction Coating \\ Reinforced with Quasicrystals for the Manufacture of Sliding Bearings. American Journal of Engineering and Technology Management. \\ Vol. 4, No. 6, 2019, pp. 79-82. doi: 10.11648/j.ajetm.20190406.11
}

Received: March 21, 2019; Accepted: June 26, 2019; Published: November 27, 2019

\begin{abstract}
The paper presents the compositions of coatings from composite materials reinforced with quasicrystals. The composition and mode of application of cold gas-dynamic deposition of antifriction coating based on composite materials reinforced with quasicrystals for the manufacture of sliding bearings have been determined and determined. Quasicrystals of the $\mathrm{Al}-\mathrm{Cu}-\mathrm{Fe}$ system, metal composite coatings based on copper reinforced with quasicrystal line particles were used for research. In the course of the work, the compositions of quasicrystal-reinforced coatings were developed, the optimal composition and modes of applying the coating by cold gas-dynamic spraying were determined. According to the optimal mode, samples were made and their mechanical and tribological properties were investigated.
\end{abstract}

Keywords: Gas-Dynamic Spraying, Quasicrystals, Coatings from Composite Materials, Tribological Properties

\section{Introduction}

In tribology and materials science of anti-friction composites, a number of problems can be distinguished, reflecting current trends in this field of knowledge, the solution of which is necessary to ensure scientific and technical progress. The greatest efforts of the developers are focused on the creation of polymeric antifriction materials intended for work in the mode of hydrodynamic friction. Rolling and sliding bearings with anti-friction coatings are the most efficient designs, allowing to significantly increase the power and reliability of the friction units of machines.

The main technical advantages when working in an environment of oil antifriction materials based on metal polymers, ceramopolymers and composite materials is the smaller difference between static and dynamic friction coefficients, which significantly improves the dynamics of transients in machines, as well as quiet operation and low specific gravity.

The braking energy of highly loaded systems is released in the zone of friction and is converted into thermal energy and the energy of surface destruction. In this regard, antifriction materials must meet the following requirement: have a high thermal conductivity, low friction coefficient, stable to a temperature of $450-500^{\circ} \mathrm{C}$, low parameters for wear, high elastic and strength characteristics.

For the operation of friction units at temperatures up to $500^{\circ} \mathrm{C}$, ceramic and composite materials based on silicon carbide and titanium carbonitride are fully satisfied, the studies to determine the physicomechanical properties of which were carried out in this work.

\section{Development of the Composition and Modes of Coating by the Method of Cold Gas-Dynamic Spraying}

The coating was carried out using the method of cold gasdynamic spraying. Testing the modes of application of the compositions of powder materials was carried out on flat 
specimens with dimensions of $90 \times 20 \times 2 \mathrm{~mm}$. The working surface of the samples was subjected to grinding and then jetabrasive treatment before spraying. The coating was carried out on the installation "Dimet-403", using air as the working fluid. The speed of the gas-powder mixture at the nozzle exit is in the range of $650-850 \mathrm{~m} / \mathrm{s}$. The deceleration temperature of the supersonic jet ranged from 150 to $350^{\circ} \mathrm{C}$.

The coating was applied in a protective chamber using a ventilation system with dust cleaning. The air pressure in the pneumatic system was set in all cases equal to $0.8 \mathrm{MPa}$. Due to the low sputtering temperature, the quasicrystalline phase does not chemically interact with copper, and the high flow rate ensures that the plastic particles of copper and solid particles of quasicrystals stick to the substrate, forming strong bonds between the coating components.

For the preparation of powder mixtures, powders of quasicrystals of the VKK1B grade TU 1-595-31-1081 and copper PMS-1 GOST 4960 were used. The powder of quasicrystals was ground in a planetary mill with glass balls of two $\mathrm{mm}$ in diameter for 30 minutes, at a ratio of grinding bodies (balls) and 10: 1 powder by weight. Was obtained powder with a dispersion of less than 3 microns.

Stirring of the powders was carried out in a turbulent mixer for 1 hour.

The concentrations of the initial elements were determined depending on the volume fraction of quasicrystals. The concentration of the original elements was determined by the formula:

$$
\% m A=\frac{\% v A \cdot \rho A}{\% v A \cdot \rho A+\% v B \cdot \rho B} \cdot 100 \%
$$

where $\%_{\mathrm{m}} \mathrm{A}$ - mass fraction of quasicrystals

$\%_{\mathrm{v}} \mathrm{A}$ - volume fraction of quasicrystals

$\rho \mathrm{A}-$ quasicrystal density

$\%_{\mathrm{v}} \mathrm{B}$ - volume fraction of copper

$\rho \mathrm{B}$ - copper density.

Several compositions of powder mixtures with different contents of quasicrystals were tested, for spraying at the Dimet 403 installation, optimal spraying conditions were determined.

The obtained samples were rectangular steel plates $(90 \times 20 \times 2)$ with composite coating, $0.5 \mathrm{~mm}$ thick. The surface after grinding has copper-pink colors, with small defects in the form of uneven deposition.

Coating sections were made. Metallographic studies on an optical microscope with an increase of $\times 950$ showed that the particles of quasicrystals are evenly distributed in the copper matrix, the coating porosity is negligible. However, the adhesion strength of particles of quasicrystals with a copper matrix turned out to be low, probably due to the low surface energy characteristic of quasicrystals. During grinding, quasicrystals crumble out of the matrix.

Coating composition has been adjusted. Iron powder PZhR2.200.22 GOST 9849 was introduced into the powder mixture. Industrial powder was dispersed into fractions on sieves with 0.25 and $0.125 \mathrm{~mm}$ cells. The obtained average fraction was used. Large, spherical particles of iron are not included in the composition of the coating, since they do not have time to acquire the speed necessary for plastic deformation and welding in an air jet. At the same time, they have substantial kinetic energy in order to additionally compact and deform the coating [1].

The amount of added iron powder was selected experimentally. An excess of iron particles in the mixture leads to a strong deformation of the applied layer, the appearance of cracks in the coating and a decrease in adhesion with the substrate until flaking (Figure 1). Insufficient amount - does not give the effect of increasing the adhesion strength of quasicrystals with a copper matrix.

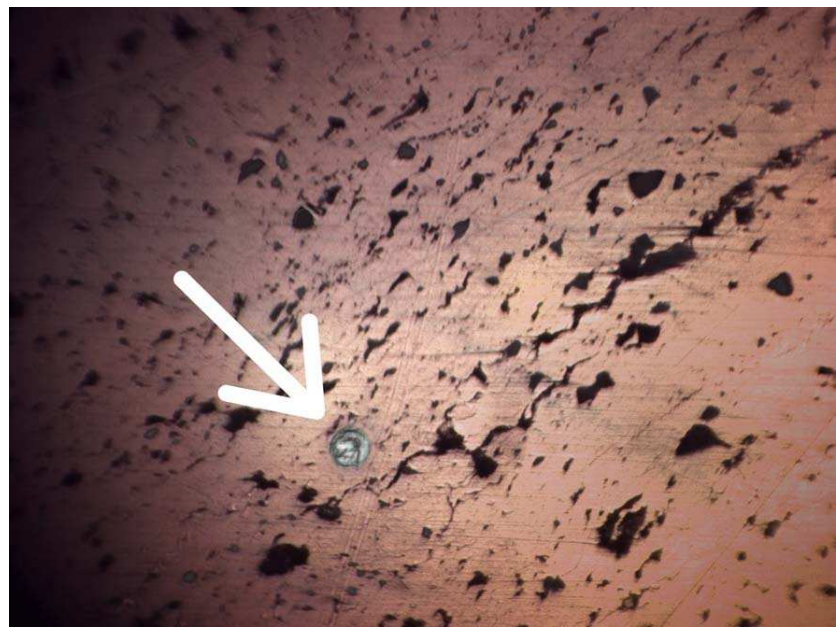

Figure 1. Cracking coating. The arrow shows a fixed particle of iron.

It was found that by adding iron powder in an amount of about $10 \%$ by weight, while simultaneously lowering the deposition temperature to $250^{\circ} \mathrm{C}$, the coating is of satisfactory quality, but its adhesion to the substrate is somewhat reduced (Figure 2). To improve adhesion, it was decided to apply a pure copper underlayer before coating.

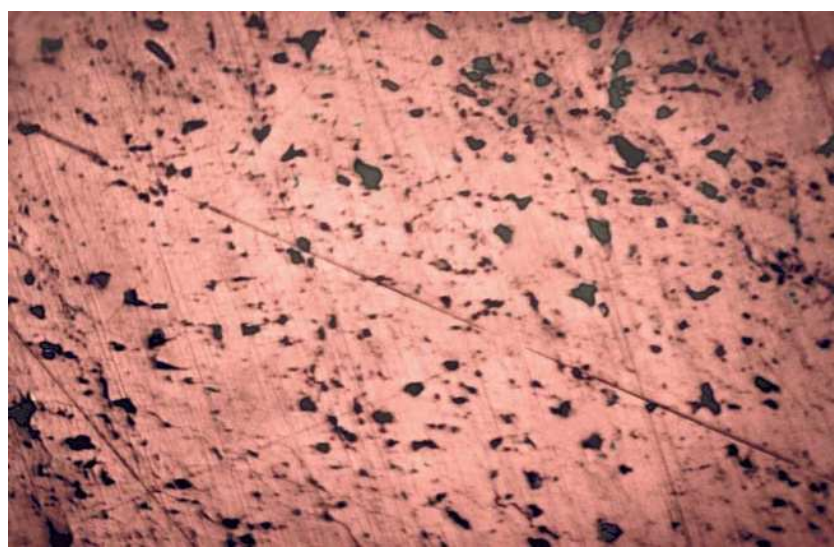

Figure 2. Coating the optimal composition.

The following composition of the powder mixture was finally adopted: copper $-78.2 \%$, quasicrystals $-12.7 \%$, iron - $9.1 \%$ by weight. Given that iron powder is not included in the coating, this corresponds to $14 \%$ by weight of quasicrystals or $30 \%$ by volume. 
Coating mode on the Dimet 403 installation: temperature $250^{\circ} \mathrm{C}$, powder supply - not more than the second position of the regulator's handle.

The study of thin sections of the obtained coatings confirmed the absence of noticeable porosity and an improvement in the adhesion of quasicrystal particles to the matrix.

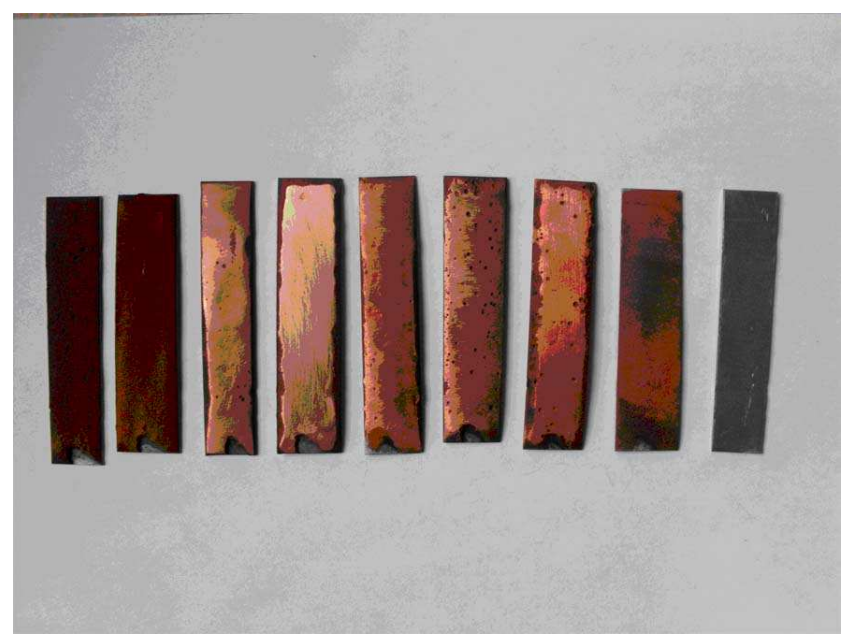

Figure 3. Samples of the coating applied by the method of cold gas-dynamic spraying on steel substrates.

\section{Determination of Mechanical and Tribological Properties of the Coating}

The adhesion of the obtained coating was evaluated by the bending method according to GOST 9.302-88. Steel plates $90 \times 20 \times 2$ in size with a coating bent at a right angle. The peeling of the coating was evaluated, the cracking was not taken into account (Figure 4). Samples showed satisfactory adhesion (test report No. 3615/31) [2].

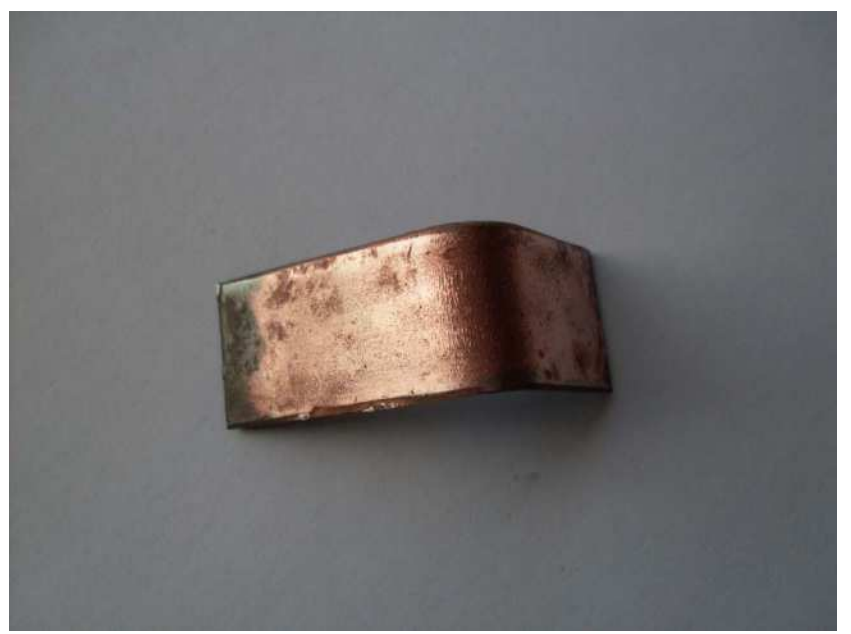

Figure 4. Sample coating after adhesion assessment by bending.

The microhardness of the coating was determined according to GOST $9450-76$ on a PMT-3 microhardness meter with a load of $20 \mathrm{~g}$. The microhardness of the copper matrix and the quasicrystal grains on two microsections of the coating was separately determined. Microhardness ranged from 388 to $407 \mathrm{MPa}$ for the matrix and from 1290 to 1393 for quasicrystal grains (protocol No. 3612/31) [3, 4].

The tribological properties of the coating were investigated. Friction and wear tests were carried out (test report No. 3565/05). For this purpose, samples were made with a coating of a metallic composite material based on copper with a quasicrystal content of $14 \%$ by weight. The samples were steel rings with a diameter of $28 \mathrm{~mm}$ with a coating applied on the end part (Figure 5) $[5,6]$.

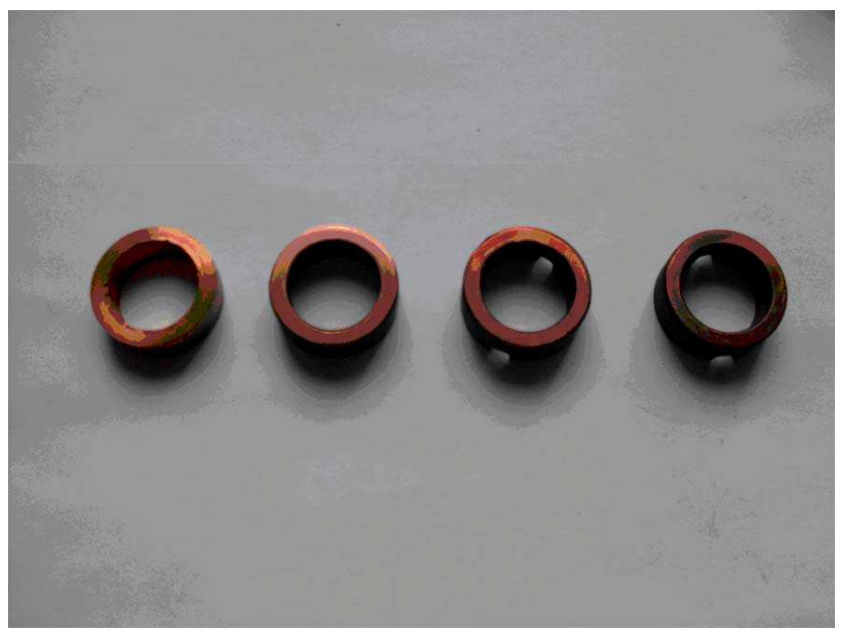

Figure 5. Samples of the coating on the end parts.

Tests for wear resistance were carried out in a pair with a counterbody from steel $30 \times 13$ on an I-47 testing machine according to MM 1.595 5315 for one hour at an axial load of $30 \mathrm{MPa}$ and a movement speed of $0.1 \mathrm{~m} / \mathrm{s}$ in a dry environment. The average coefficient of friction is 0.48 . Counterbody wear on average $408 \mathrm{mg}$ / hour [7].

\section{Conclusion}

As a result of the research, experimental samples of coatings reinforced with particles of quasicrystals of the Al$\mathrm{Cu}-\mathrm{Fe}$ system were created, The optimal concentrations of the initial elements were determined depending on the volume fraction of quasicrystals. Investigation of mechanical and tribological properties of prototypes-found that the adhesion to the substrate is satisfactory, the coating is dense, the microhardness of the copper matrix from $1393 \mathrm{MPa}$ to $407 \mathrm{MPa}$, for quasi-crystal grains from 1290 to $1393 \mathrm{MPa}$, which makes it possible to effectively use this coating in friction units of machines, increasing the power and reliability of structures.

\section{References}

[1] B. Zakharov, M. G. Trofimov, L. I. Guseva, et al. On the adhesion strength of coatings applied by plasma spraying // Powder Metallurgy. 1970. №11. Pp. 71-76. 
[2] Denisov L. V., Boytsov A. G., Siluyanova M. V. Providing operational properties of parts and components of a gasturbine engine by local surface doping // Herald of Samara University. Aerospace engineering, technology and engineering. № 2. Pp 19-24.

[3] Nizovtsev V. E., Silchenko O B, Siluyanova M. V. et al. Some estimates of the stress-strain state of ceramic composite materials with regard to technological pores // Bulletin of the Bryansk State Technical University No. 5. Pp. 52-63.

[4] Boitsov A. G., Siluyanova M. V., Kuritsyna V. V. ElectricDischarge Milling of Small Airplane-Engine Components (Technological capabilities of processing by electroerosive milling of small-sized parts and elements of aircraft engines) // Russian Engineering Research. 2018. T. 38.№ 7. pp. 552-556.

[5] Silchenko, OB, Siluianova, MV, Nizovtsev, V. E., Klimov, DA, Kornilov, A. A. On the prospects for the use of nanostructured heterophase polyfunctional composite materials in the aircraft engine industry // Materials Science. 2018.№1. Pp. 50-57.

[6] Siluyanova M. V., Fertikov A. O. Improving the friction units of power plants by applying sprayed coatings of ceramic composites // Vestnik Samara University. Aerospace engineering, technology and engineering. 2018. No. 2. Pp. 122-131.

[7] Sil'chenko O. B., Siluyanova M. V., Kuritsyna V. V. Diagnostics of Dimensionally Controlled Microgrinding to Meet Quality Specifications // Russian Engineering Research. 2018. T. 38. № 8. pp. 604-609.

[8] Musil J., Vicek J. // 5th Conf. on Modification of Materials with Particle Beams and Plasma Flows. Tomsk, 2000. P. 393398.

[9] Yu. A. Abuzin, A. S. Yudin "Investigation of the features of quasicrystals when creating materials for space, aviation, motor engineering and other sectors of the national economy" of FSUE "VIAM" in the collection of reports of the first AllRussian meeting of quasicrystals, April 2003.

[10] Scientific basis of the technology of cold gas-dynamic spraying (CGN) and the properties of the deposited materials: monograph / A. P. Alkhimov, V. F.

[11] Application for OTR №7718 "Method for the production of composite coatings" dated 10/20/2009.

[12] Kelly P. J., Arnell R. D. // Vacuum. 2000. Vol. 56. P. 159-172.

[13] Shiryaev S. A., Atamanov M. V., Guseva M. I., Martinenko Yu. V., Mitin A. V., Mitin V. S., Moskovkin P. G. // Preporation and properties of composite coating based on metal-carbon with nanocrystalline structure // Journal of Technique 2002, T. 72, v. 2.

[14] Mitin V. S., Sharipov E. I., Mitin A. V. // High deposition rate magnetrons - innovative coating technology: key elements and advantages // Surface Engineering 2006 Vol. 22 no 1.

[15] Shelekhov E. V., Sviridova T. A. // Programs for X-ray analysis of polycrystals // Metal Science and Heat treatment, 2000. T. 42. № 7-8. p. 309-113.

[16] Kryukova L. M., Makalkina E. A., Salikhov S. V. // Parameter estimation of nanostructured state. I. An integrated approach and mathematical research and treatment experimental date //Journal of Materials Science 2010 v. 8

[17] Portnoi V. K., Leonov A. V., Mudretsova S. N., and Fedotov S. A. // Formation of Nickel Carbide in the Course of Deformation Treatment of Ni-C Mixtures //The Physics of Metals and Metallography 2010. v. 109, N2 p. 153-161.

[18] Krawietr Z., Wehner B., Sebalt T., Dietsch R. // Investigation of Termal Agingof Ni/C Multilayers by X-Ray Methods // Mater. Sci. Forum. 1994, v. 166-169. p. 1247-1253. 